\title{
Sliding wear behavior of magnetron sputtered chromium carbide thin films
}

\author{
Nasser Eddine Beliardouh \\ Laboratoire Ingénierie des Surfaces (LIS), Université Badji Mokhtar, Annaba, Algeria \\ Corinne Nouveau \\ Laboratoire Bourguignon des Matériaux et Procédés (LaBoMaP), Arts et Métiers ParisTech de Cluny, Cluny, France, and \\ Hakan Kaleli \\ Faculty of Mechanical Engineering, Automotive Division, Yıldız Technical University, Istanbul, Turkey
}

\begin{abstract}
Purpose - The purpose of this technical paper is to investigate the friction and wear behavior of inexpensive and durable cutting tools, developed for wood machining using duplex treatment.

Design/methodology/approach - $\mathrm{Cr}-(\mathrm{WC}-\mathrm{Co})$ coatings were deposited onto carburized low-alloy steel substrate by a reactive magnetron sputtering. The total coating thickness was approximately $2 \mu \mathrm{m}$. Unlubricated wear tests have been performed using a disc sample sliding against an alumina ball $\left(\mathrm{Al}_{2} \mathrm{O}_{3}\right)$ and a wood (beech) pin.

Findings - The paper provides information about the effect of duplex treatment on the surface properties of low-alloy steel against wood and offers practical help for the researchers in coating topic.

Originality/value - Experimental results showed that sliding wear properties of the selected coatings are strongly dependent on the counter-face material. When tested against alumina balls, the wear mechanisms are oxidative wear followed by a combination of adhesive and abrasive wear, while a combination of an oxidative and adhesive wear was the main wear mechanism observed against a wood pin.
\end{abstract}

Keywords Coatings, Wear, Friction, Wood, Cutting tool, Duplex-treatment

Paper type Research paper

\section{Introduction}

Nowadays, a combination of several and sometimes conflicting mechanical properties of steels exists. A promising way to cope with these requirements is to apply a duplex treatment. It consists in the combination of thermo chemically treated bulk steel, and then covered with thin hard coatings. Low-carbon steels are potential candidates for such performances because they exhibit good ductility and form but also low yield strength and low resistance to surface degradation processes. Thermochemical treatments such as nitriding, carburizing, boriding, carbonitriding, etc., have been used to improve the surface properties, i.e. mechanical strength as well as moderate wear and corrosion resistance. At the same time, the steel properties (resilience, ductility) were kept unchanged at its core. In the case of steel carburizing technique (Stickels et al., 1991), the chemical composition of the surface changed by increasing the surface concentration of carbon. As a result, the microstructure of the surface is modified. The samples are exposed in an atmosphere rich in carbon under high temperature above $910^{\circ} \mathrm{C}$ during a relatively long duration. Then, the carbon atoms diffuse into the core to produce a carbon-enriched layer. Following carburizing, the steel is quenched to low temperature to increase the hardness of the carbon-enriched surface layer.

As mentioned above, to further improve the surface steel performances, they must be covered with an appropriate coating. A wide range of metal transition-based coatings $(\mathrm{Cr}$, $\mathrm{Ti}, \mathrm{Al}$ ), deposited as thin layers (few micrometers thick), of different compounds (carbides, nitrides, oxides) are proposed in the literature. However, to improve the coating functionality, the adhesion between the heat-treated steel substrate and the coating is a main property. Here, the deposition method is a key factor to choose, because it can provide either a high- or a low-quality coating. For example, when a high wear resistance is required, in contrast to most other coatings, tungsten-carbide-based coatings can be an appropriate choice. Indeed, because of their high mechanical properties, they are useful in a wide variety of industrial applications. This is due to the presence of the hard WC grains in the coatings that lead to high coating hardness, while the metal binder (Co, $\mathrm{Ni}$ or $\mathrm{Co}-\mathrm{Cr}$ ) supplies the necessary coating toughness (Zhao et al., 2004). Besides, PVD processes are also recommended for the eco-friendly aspect to avoid

The authors would like to thank Dr M.J. Walock, Dr A. Zairi, Dr P. Jacquet, D. Lagadrillère and R. Fliti for their support in the experimental work. 
environment damages. Usually a WC-Co-Cr cermet coating is synthesized by high-velocity oxygen fuel thermal spraying method (Ping Wu et al., 2012). On the other hand, considerable research studies have been previously conducted to understand the mechanism of wear of uncoated and coating tools (Findik, 2014). However, a few works on WC-Cr coatings elaborated by radio frequency ( $R F$ ) magnetron sputtering are reported in the literature (Walock et al., 2012).

The second part of this study is focused on the friction and wear properties of the treated samples and especially concerns the wood-tools interaction. Indeed, because of a good machinability allowing high cutting speed and few wastes, wood allows a good productivity. Timber is a heterogeneous material; thus, tools used in the timber industry must exhibit high resistance to abrasion and mechanical strokes. Besides, most of the carbide tools used in the metal cutting industry are coated, which causes an extra cost (Yigit et al., 2008). Cemented carbides are common materials used in this field. However, a lot of coated tools are proposed as substitutes in the literature on this topic (Eblagon et al., 2007; Benlatreche et al., 2009; Gilewicz et al., 2010, 2013; Settineri and Faga, 2006).

In previous studies (Beliardouh et al., 2014a, 2014b), mechanical and physical properties of low-alloy steel substrates duplex-treated were reported. The duplex treatment consists of carburizing followed by $\mathrm{RF}$ magnetron sputtering deposition of $\mathrm{Cr}-(\mathrm{WC}-\mathrm{Co})$ coatings. The wear performances of samples sliding against alumina and WC balls were analyzed. The main conclusion was a change in wear mechanisms due to microstructural difference between coatings (Cr:W ratio). On another hand, when wood (beech) was a static partner (Beliardouh et al., 2014a, 2014b), the effect of a duplex treatment was clearly demonstrated to improve the wear resistance of the substrate.

In this work, the wear performances of duplex-treated low-alloy steel substrates were conducted, in dry conditions, when wood and alumina are the counter-face materials under applied load (F) equal to $5 \mathrm{~N}$. All tribological parameters were kept constant and similar to our previous works. In addition, the obtained results of coated and uncoated samples are compared. These studies were conducted in view to apply them in wood machining (Nouveau et al., 2005, 2011).

\section{Materials}

\section{Sample preparation}

Carburized low-alloy steel (Commercial DIN18CrMo4) was used as substrate (Beliardouh et al., 2014a, 2014b). Thermochemical treatments were conducted to create a hardness profile between the surface and the core of the steel substrate. Then, the substrates were coated with a single layer by co-sputtering of a WC-Co and a Cr target in a non-reactive atmosphere RF magnetron system. The system has been described in previous works (Beliardouh et al., 2014a, 2014b).

A Cr under-layer of $0.5 \mu \mathrm{m}$ thickness was realized to improve the adhesion at the interface with the steel substrates.

The total thickness of the coatings is about $2.3 \mu \mathrm{m}$, including the $\mathrm{Cr}$ under-layer. The hardness $(\mathrm{H})$ and Young's modulus (E) of the layers are $26.4 \mathrm{GPa}$ and $324.1 \mathrm{GPa}$, respectively. Their critical load $\left(\mathrm{L}_{\mathrm{C}}\right)$ was $32.5 \mathrm{~N}$ and their chemical composition (at. per cent) obtained by EDS microanalysis was: $\mathrm{C}=22.3 ; \mathrm{Cr}=41.6 ; \mathrm{Co}=8.3 ; \mathrm{W}=27.1$ and $\mathrm{O} \sim 0.7$.

Using a 3D optical profilometer (VEECO, Wyko NT-1100), the roughness $(\mu \mathrm{m})$ of the uncoated steel was determined [Arithmetic average $\mathrm{R}_{\mathrm{a}}( \pm 0.03)=0.06$; and the root mean square (RMS) $=0.11 \pm 0.02]$. The roughness of the $\mathrm{Cr}-(\mathrm{WC}-\mathrm{Co})$ coatings was $\mathrm{R}_{\mathrm{a}}=0.05 \pm 0.03 \mu \mathrm{m}$ and the RMS $=0.07 \pm 0.02 \mu \mathrm{m}$.

The characteristics of the wood specimen used as static partners are as follows:

Scientific designation: Fagus sylvatica (fagaceae family); UK appellation: beech; density $=0.71$; Monnin hardness (NF B 51-013) $=4.1$.

Roughness $(\mu \mathrm{m}):[\operatorname{Ra}( \pm 3.5)=11.7$; RMS $( \pm 2.1)=$ 15.07].

\section{Methods}

\section{Tribological tests}

Tribological tests were conducted with a CSM rotative tribometer, using a ball-on-disc configuration in which the specimen acts as the disc that turns in contact with a static partner (alumina ball or cylinder wood pin) without lubrication. Before each test, the samples were carefully polished and ultrasonically cleaned in acetone. During the tests, the following parameters were kept constant: sliding speed $(v=2 \mathrm{~cm} / \mathrm{s})$, normal load $(\mathrm{F}=5 \mathrm{~N})$ and track radius $(r=4 \mathrm{~mm})$. The sliding distance was long enough to produce a breakdown of the coating $(200 \mathrm{~m})$. The tests were conducted at room temperature $\left(\sim 25^{\circ} \mathrm{C}\right)$ and 40 per cent humidity. Three (03) wear tests were performed per sample.

To compare the wear resistance of the coatings, specific wear rates were calculated according to equation (1):

$$
\mathrm{K}=\mathrm{V} / \mathrm{L} \cdot \mathrm{F}
$$

Where $\mathrm{K}$ is the specific wear rate $\left[\mathrm{mm}^{3} / \mathrm{Nm}\right], \mathrm{V}$ is the wear volume $\left[\mathrm{mm}^{3}\right], \mathrm{F}$ is the normal load $[\mathrm{N}]$ and $\mathrm{L}$ is the sliding distance $[\mathrm{m}]$.

\section{Surface analysis}

A 3D optical profilometer was used to measure the average wear volume and consequently to calculate the coatings' wear rate. Due to the variation of the depth along the length of the wear track, numerous depth measurements (perpendicular to the length of the track) were measured. Commercial alumina balls were used as counterparts (hardness $\mathrm{H}=16.14 \mathrm{GPa} ; \mathrm{R}_{\mathrm{a}}$ and RMS surface roughness were $0.178 \pm 0.03 \mu \mathrm{m}$ and $0.256 \pm 0.03 \mu \mathrm{m}$, respectively). The wear rate of the ball was estimated by calculating the volume of its spherical crown loss with an optical microscope.

To analyze the wear process and consequently the wear mechanisms, the worn surfaces and wear debris generated during these tests were observed by SEM (Jeol 5900LV) and analyzed by EDS/WDS. All measurements and evaluation procedures for material volume loss were conducted according to ASTM G99-95a standards (ASTM Designation G99-95a, 2010). 


\section{Results}

Optimization of the interface was adopted to create a properties gradient that will ensure good adhesion of the subsequently deposited hard coatings. Figure 1 ( $a$ and $b$ ) shows a cross-sectional view of the thermo chemically and coated samples. Two regions are clearly distinguished:

1 Cr-(WC-Co) coating as top layer; and

2 the steel matrix which exhibits an hardness profile corresponding to microstructural changes due to thermochemical treatment, i.e. after quenching, carbonrich layer at the steel surface transforms into tempered martensite, fine carbides $(\mathrm{Fe}, \mathrm{Cr})_{3} \mathrm{C}$ and some retained austenite.

\section{Coefficient of friction evolution}

Friction test results conducted on the surface of uncoated and Cr-(WC-Co)-coated samples (disc) versus both alumina balls and beech wood pins as a function of sliding distance/cycles under a $5 \mathrm{~N}$ load are illustrated in Figure 2(a and b). In coupling carburized surfaces versus static partners, both curves in Figure 2(a) show the typical running-in period characterized by an initial transient state of $\sim 250$ cycles, followed by a friction coefficient increase and a final gradual-steady state of $>2000$ cycles. The initial transient state corresponds to the contact with high asperities between surfaces of antagonists. The coefficient of friction (COF) value at the steady state was relatively higher $(1.1 \pm 0.05)$ for the steel/wood contact than for the steel/alumina contact $(0.75 \pm 0.05)$.

When sliding against alumina, Figure 2(b), the Cr-(WCCo) coating showed a short period of running-in friction followed by a stabilized friction at steady state $(0.6 \pm 0.02)$ until 3,000 cycles and, finally, the friction coefficient increases to a constant value of $0.7 \pm 0.03$. The latest state corresponds to the delamination of the film. Thus, the ball-on-disc tests showed that the coatings are completely worn prior to the end of the test.

The friction coefficient evolution registered in tests against wood pins shows two steps. An initial running-in period, afterwards it becomes constant (stable) at very low values $(0.2 \pm$ 0.01 ) and presents a long stabilized steady state until the end of the test.
Consequently, it is clearly shown that the counterpart material has a main influence on the tribological behavior of the coating. The wear of coatings against alumina was obviously higher than the wear of coatings against beech wood. In contrast, the $\mathrm{Cr}-(\mathrm{WC}-\mathrm{Co})$ coatings presented a very low COF against the wood pin, which is very promising for wood machining applications of these layers.

\section{Wear mechanism analyses}

To study the wear mechanisms of the tribological couples, the worn surfaces were observed by SEM and analyzed by EDS. When the surface of the uncoated sample rubs against an alumina ball, SEM/EDS analysis of the wear track reveals different regions: dark and light regions, as shown in Figure 3.

When the surface of the uncoated sample rubs against a wood pin, SEM/EDS analysis of the wear track reveals different regions: dark and light regions, as shown in Figure 4. However, all regions contain oxygen, substrate elements ( $\mathrm{Fe}$, $\mathrm{Cr}$ ) and wood element (C, Ca, Na, Cl, Si). Grooves and a low quantity of wear debris are also shown on wear track of steel samples. Wear scar of wood pin indicates the presence of debris containing $\mathrm{Fe}, \mathrm{Cr}$ and $\mathrm{O}$ in addition to chemical elements of wood. Adhesion of very small wood fibers spilling from the pin, in form of tiny "wood chips" on worn steel surface, do not affect wear process because after compressed air cleaning of steel surface, none of the wood elements was detected inside the wear track. Only oxidized wear debris trapped in the sliding contact caused abrasive wear of the metallic surface. So, the wear mechanism in this case seems to be an oxidative wear followed by an abrasive wear. Figure 5 shows results of SEM observations/EDS analyses of coated samples in contact with wood pins and alumina balls. Finally, no sign of adhesive wear was observed on the carburized surfaces. The main wear mechanisms are oxidization and abrasion.

When sliding against wood as a static partner, a large wear track was revealed and no wear debris was observed (Figure 5(a)). Three distinctive regions "rings" can be shown on the wear track. In the first one (point 1; Figure 5(a)), only elements of the coating could be detected, so the coating was not entirely removed from the substrate. Substrate elements ( $\mathrm{Fe}, \mathrm{Cr}$ ) as wood elements $(\mathrm{Na}, \mathrm{C})$ and oxygen $\mathrm{O}$ were detected in the

Figure 1 Optical cross-sectional microstructure of samples

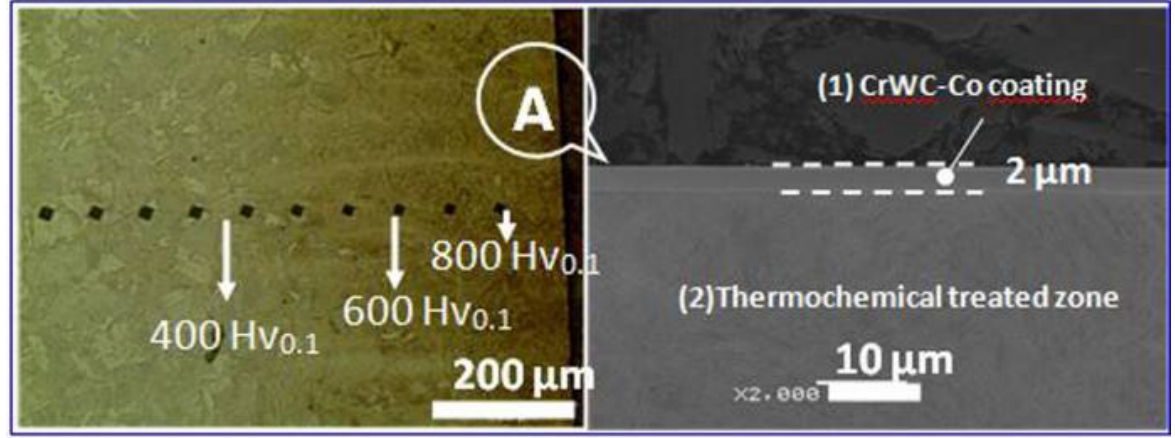

(a) (b)

Notes: (a) Steel substrate showing variation in hardness from the outer layer to the bulk;

(b) SEM image of a $\mathrm{Cr}-(\mathrm{WC}-\mathrm{Co})$ coating on steel substrate 
Figure 2 Friction coefficients (COF) as a function of the number of sliding cycles for (a) the uncoated and (b) coated substrates sliding against alumina and wood counterparts

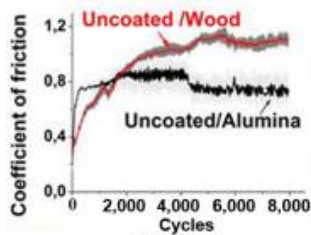

(a)

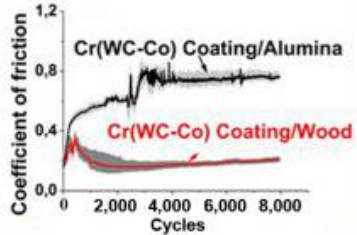

(b)
Figure 3 SEM image of the wear track after a wear test of a carburized sample in contact with an alumina ball. White arrows indicate grooves parallel to sliding direction (SD)

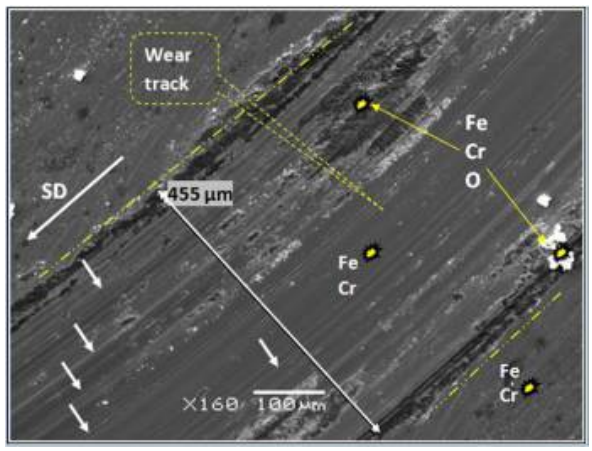

Figure 4 SEM images of (a) the wear track after a wear test of a carburized sample (b) wear scar of wood pin

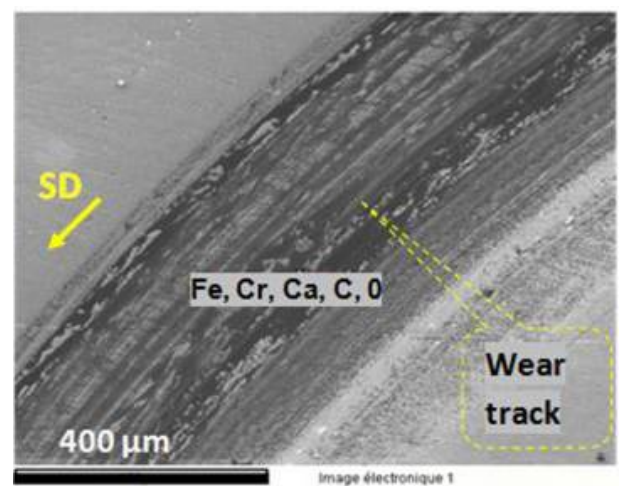

(a)

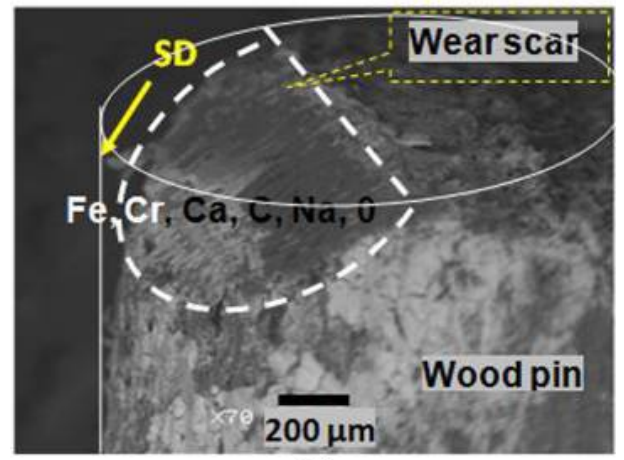

(b)
Figure 5 SEM images of the wear tracks of $\mathrm{Cr}-(\mathrm{WC}-\mathrm{Co})$-coated samples after sliding against wood pin (a) and alumina ball (b) (black arrows: grooves parallel to sliding direction [SD] and white arrows: coating peeling off); (c)-(d) corresponding cross-sectional 2D profiles of the wear track; (e)-(f): wear scars of wood pin and alumina ball, respectively
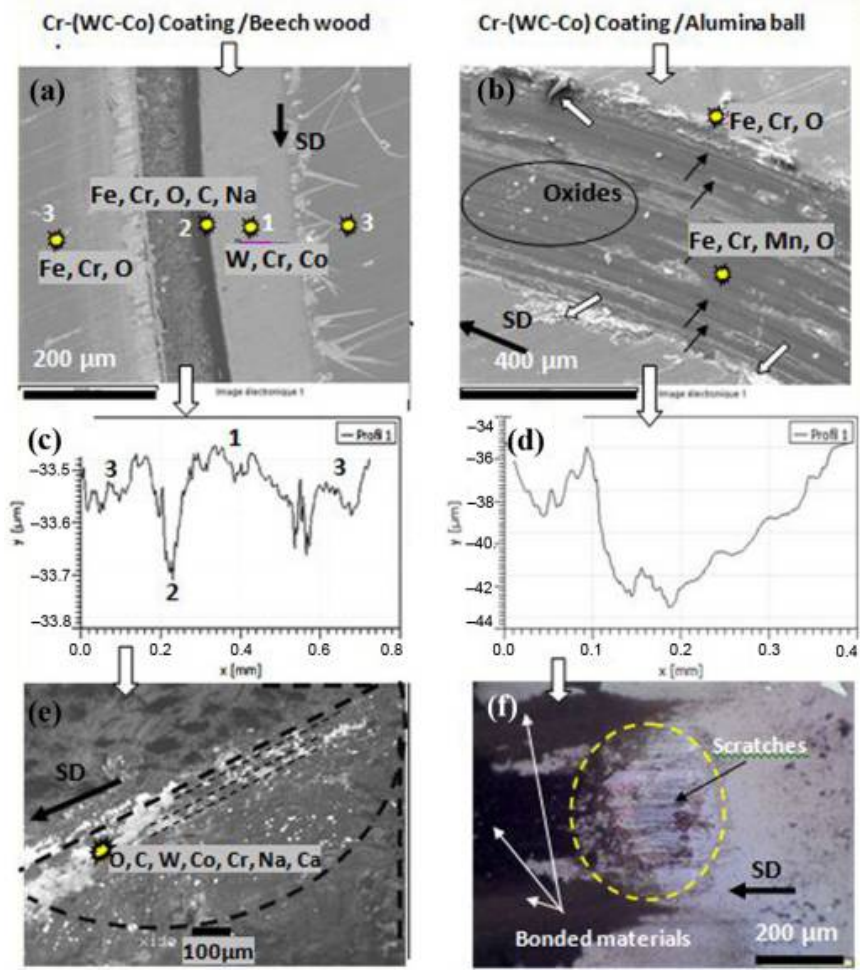

second "ring" (point 2; Figure 5(a)), while elements of substrate and oxygen were found in the third area indicated by point 3 in Figure 5(a).

Consequently, the coating was destroyed and removed along this area as indicated in the $2 \mathrm{D}$ wear profile (point 2; Figure 5(c)). SEM observation/EDS analysis of the wood pin wear scar (Figure 5(e)) indicates that oxidization occurred during the sliding contact. Besides, the WC-Co coating's material was transferred to the wood pin surface as debris and participated in the friction process. The wear mechanism was a combination of an oxidative and adhesive wear.

When alumina balls are static partners, as shown in Figure 5(b), grooves and scratches parallel to sliding direction are observed as well as wear debris accumulated on the edge of the wear track. Inside the wear track, no trace of coating can be found. This result was confirmed by the $2 \mathrm{D}$ wear profile (Figure $5(\mathrm{~d})$ ) that shows the difference between the effect of both wood pin (Figure 5(c)) and alumina ball (Figure 5(d)) on wear damage of the duplex-treated samples. It was confirmed here that the coating presenting the lowest COF (against wood pins) is more efficient during sliding tests and not completely delaminated.

In Figure 5(b), the delamination of the coating is obvious thanks to the presence of wear debris that led to increase the friction forces between the surfaces in contact. Moreover, the ball wear scars were completely covered by adhesive wear 
debris (as shown in Figure 5(f)). In addition, scratches are clearly visible, as revealed by optical microscopy.

Figure 6(a) gave more details on damaged surface after wear tests with alumina as the counterpart. SEM observations/EDS analysis indicated that there is no area free of oxides in the entire wear track and a third-body appeared, as observed in Figure 6(b).

Then, it was observed that under a load of $5 \mathrm{~N}$, there was a higher contact pressure responsible for the formation of wear debris, increasing the frictional force and, therefore, the friction coefficient.

Consequently, the main wear mechanisms are oxidation followed by a combination of adhesive and abrasive wear for the $\mathrm{Cr}-(\mathrm{WC}-\mathrm{Co})$ coatings/alumina balls couple.

From 2D profiles of the wear track, we calculated the volume loss to determine the wear rates $(\mathrm{K})$. It is known that lower the specific wear rate is, more wear resistant the coating is. Then, it was obvious that the alumina ball couples led to the highest wear. For the (uncoated steel/alumina ball) coupling, the wear rate of disc is $\mathrm{K}_{\text {disc }}=2.15 \times 10^{-6} \mathrm{~mm} 3 / \mathrm{N}$.m, while $\mathrm{K}_{\text {disc }}=1.024 \times$ $10^{-6} \mathrm{~mm}^{3} / \mathrm{N} . \mathrm{m}$ in $\mathrm{Cr}-(\mathrm{WC}-\mathrm{Co}$ )/alumina ball contact. However, the wear rate of disk for the (uncoated steel/wood pin) coupling is $\mathrm{K}_{\text {disc }}=0.648 \times 10^{-6} \mathrm{~mm}^{3}$ N.m. The lowest $\mathrm{K}$ values are obtained in the case of $\mathrm{Cr}-(\mathrm{WC}-\mathrm{Co})$-coated samples sliding against wood pin $\left(\mathrm{K}_{\text {disc }}=0.19 \times 10^{-6} \mathrm{~mm}^{3} / \mathrm{N} \cdot \mathrm{m}\right)$.

The wear rate of alumina ball is $\mathrm{K}_{\text {ball }}=0.154 \times 10^{-6} \mathrm{~mm}^{3} /$ $\mathrm{N} . \mathrm{m}$ in (uncoated steel/alumina ball) coupling and $\mathrm{K}_{\mathrm{ball}}=$ $2.95 \times 10^{-6} \mathrm{~mm}^{3} / \mathrm{N} . \mathrm{m}$ in (Cr-(WC-Co/alumina ball) contact. The maximum wear rate was obtained in $(\mathrm{Cr}-(\mathrm{WC}-$ Co)/wood) pin contact: $\mathrm{K}_{\text {pin }}=16.68 \times 10^{-6} \mathrm{~mm}^{3} / \mathrm{N} . \mathrm{m}$, while $\mathrm{K}_{\text {pin }}=11.84 \times 10^{-6} \mathrm{~mm}^{3} / \mathrm{N} . \mathrm{m}$ in (uncoated steel $/$ wood pin) coupling.

\section{Discussion}

Comparative studies between untreated substrate $(\mathrm{H} \sim 7.8 \mathrm{GPa})$ and duplex-treated samples $(\mathrm{H} \sim 26 \mathrm{GPa})$ can be summarized as follows: the wear rate of disc is reduced byh approximately 52 and 70 per cent when the duplex-treated samples rub against alumina ball and wood pin, respectively. On the other hand, the wear rate of the static partners varies from about 91 and 41 per cent in the case of alumina ball and wood pin, respectively. The abovementioned results are consistent with earlier works (Dogan et al., 2002a, 2002b, 2003), who noted that increase of the hardness led to decrease in the volumetric wear (or the wear rate). According to these authors, a lower volumetric wear of the discs can be due to the microstructure modifications in the substrate after surface treatment. Those microstructural

Figure 6 (a) SEM images of the wear track after wear test of $\mathrm{Cr}-(\mathrm{WC}-\mathrm{Co})$ /alumina balls and (b) details of area " $\mathrm{A}$ ": all areas are rich in oxygen

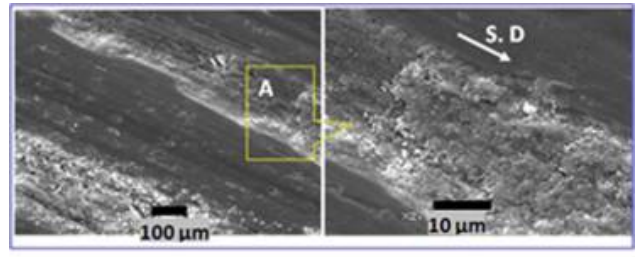

(a)

(b) modifications led to an increase of the mechanical properties, especially a higher hardness, i.e. internal residual stresses and dislocation density. As a consequence, one can suppose a decrease of the adhesive forces and then of the volumetric wear of the treated samples.

According to the obtained results:

- it is obvious that the friction and wear of the discs depend largely on the materials type;

- in comparison to previous work (Beliardouh et al., 2014a, 2014 b), the increase of the applied normal load from 1 to $5 \mathrm{~N}$ had no influence on the wear mechanisms; and

- finally, in agreement with Dogan et al. (2002a, 2002b, 2004), the working environment and the friction type are two main parameters influencing the strength of materials in friction conditions.

\section{Conclusions}

The friction tests conducted on the surface of coated steel substrates were analyzed and compared to those of uncoated steel-base samples. The conclusions are as follows:

- when sliding against a wood pin, uncoated sample surface suffered an oxidative wear followed by an abrasive wear while protected with a $\mathrm{Cr}-(\mathrm{WC}-\mathrm{Co})$ coating; the wear mechanism was a combination of an oxidative and adhesive wear; and

- when sliding against alumina balls, analysis of the worn surfaces and wear debris of the duplex-treated samples reveals that the main wear mechanisms are oxidative wear followed by a combination of adhesive and abrasive wear, while uncoated samples undergo a mixture of oxidative and abrasive wear.

\section{References}

ASTM Designation G99-95a (2010), "Standard test method for wear testing with a Pin-on-Disk apparatus", ASTM International, West Conshohocken, PA. doi: 10.1520/ G0099-05R10.

Beliardouh, N.E., Nouveau, C. and Kaleli, H. (2014a), "Wear performance of duplex treated low alloyed steel against wood (beech) as static partner", fournal of Balkan Tribological Association, Vol. 20 No. 1, pp. 70-78.

Beliardouh, N.E., Nouveau, C., Walock, J.M. and Jacquet, P. (2014b), "A study of the wear performance of duplex treated commercial low-alloy steel against alumina and WC balls", Surface Coating Technology, Vol. 259, pp. 483-494.

Benlatreche, Y., Nouveau, C., Marchal, R., FerreiraMartins, J.P. and Aknouche, H. (2009), "Applications of CrAlN ternary system in wood machining of medium density fiber board (MDF)", Wear, Vol. 267 No. 5, pp. 1056-1061.

Dogan, H., Findik, F. and Morgul, O. (2002a), "Tribological properties of coated ASME 316L SS and comparison with a substrate", Industrial Lubrication and Tribology, Vol. 54 No. 1, pp. 5-10.

Dogan, H., Findik, F. and Morgul, O. (2002b), "Friction and wear behaviour of implanted AISI 316L SS and comparison with a substrate", Materials and Design, Vol. 23 No. 7, pp. 605-610.

Dogan, H., Findik, F. and Oztarhan, A. (2003), "Comparative study of wear mechanism of surface treated 
AISI $316 \mathrm{~L}$ stainless steel", Industrial Lubrication and Tribologv, Vol. 55 Nos 2/3, pp. 76-83.

Dogan, H., Findik, F. and Oztarhan, A. (2004), "Tribological studies of $\mathrm{ZrO}_{2}$-implanted on stainless steel substrate", Industrial Lubrication and Tribologv, Vol. 56 No. 6, pp. 341-345.

Eblagon, F., Ehrle, B., Graule, T. and Kuebler, J. (2007), "Development of silicon nitride/silicon carbide composites for wood-cutting tools", Fournal of the European Ceramic Societv, Vol. 27 No. 1, pp. 419-428.

Findik, F. (2014), "Latest progress on tribological properties of industrial materials", Materials and Design, Vol. 57, pp. 218-244.

Gilewicz, A., Warcholinski, B., Myslinski, P. and Szymanski, W. (2010), "Anti-wear multilayer coatings based on chromium nitride for wood machining tools", Wear, Vol. 270 Nos 1/2, pp. 32-38.

Gilewicz, A., Warcholinski, B., Szymanski, W. and Grimm, W. (2013), "CrCN/CrN+ta-C multilayer coating for applications in wood processing", Tribologv International, Vol. 57, pp. 1-7.

Nouveau, C., Jorand, E., Decès-Petit, C., Labidi, C. and Djouadi, M.-A. (2005), "Influence of carbide substrates on tribological properties of chromium and chromium nitride coatings: application to wood machining", $\underline{\text { Wear }}$, Vol. 258 Nos 1/4, pp. 157-165.

Nouveau, C., Steyer, P., Ram Mohan Rao, K. and Lagadrillère, D. (2011), "Plasma nitriding of 90CrMoV8 tool steel for the enhancement of hardness and corrosion resistance", Surface Coating Technology, Vol. 205 No. 19, pp. $4514-4545$.
Ping Wu, Y., Hong, S., Zhang, J., He, Z., Guo, W., Wang, Q. and Li, G. (2012), "Microstructure and cavitation erosion behavior of WC-Co-Cr coating on $1 \mathrm{Cr} 18 \mathrm{Ni}$ Ti stainless steel by HVOF thermal spraying", International fournal of Refractory Metals and Hard Materials, Vol. 32, pp. 21-26.

Settineri, L. and Faga, M.G. (2006), "Laboratory tests for performance evaluation of nanocomposite coatings for cutting tools", Wear, Vol. 260 No. 3, pp. 326-332.

Stickels, C.A. (1991), "Gas carburizing of steels", ASM Handbook ${ }^{\circledR}$, Heat Treating, ASM International Publisher, Vol. 4, pp. 312-324.

Walock, M.J., Rahil, I., Zou, Y., Imhoff, L., Catledge, S.A., Nouveau, C. and Stanishevsky, A.V. (2012), "Sputtered tungsten-based ternary and quaternary layers for nanocrystalline diamond deposition", fournal of Nanoscience and Nanotechnologv, Vol. 12 No. 6, pp. 1-7.

Yigit, R., Celik, E., Findik, F. and Koksal, S. (2008), “Tool life performance of multilayer hard coatings produced by HTCVD for machining of nodular cast iron", International 7ournal of Refractory Metals and Hard Materials, Vol. 26 No. 6, pp. 514-524.

Zhao, L.D., Maurer, M., Fischer, F., Dicks, R. and Lugscheider, E. (2004), "Influence of spray parameters on the particle in-flight properties and the properties of HVOF coating of WC-CoCr", Wear, Vol. 257 Nos 1/2, pp. 441-466.

\section{Corresponding author}

Nasser Eddine Beliardouh can be contacted at: beliardouh_23@yahoo.fr 